\title{
Ethical sensitivity and perceptiveness in palliative home care through co-creation
}

\author{
Jessica Hemberg $(\mathbb{1}$ \\ Åbo Akademi University, Finland \\ Elisabeth Bergdahl \\ Örebro University, Sweden
}

\begin{abstract}
Background: In research on co-creation in nursing, a caring manner can be used to create opportunities whereby the patient's quality of life can be increased in palliative home care. This can be described as an ethical cornerstone and the goal of palliative care. To promote quality of life, nurses must be sensitive to patients' and their relatives' needs in care encounters. Co-creation can be defined as the joint creation of vital goals for patients through the process of shared knowledge between nurses, patients and their relatives.

Aim: The aim of this study was to explore nurses' experiences of caring encounters and co-creation in palliative home care from an ethical perspective.

Research design, participants, and research context: A hermeneutical approach was used. The material consisted of texts from interviews with 12 nurses in a home care context. The method was inspired by thematic analysis.

Ethical considerations: Informed consent was sought from the participants regarding study participation and the storage and handling of data for research purposes.

Findings: An overall theme, a main theme and four sub-themes emerged. Through ethical sensitivity and perceptivity, nurses can balance their actions in the moment and change their nursing care actions according to the patient's wishes through co-creation in encounters. Here the time is crucial, as the time needed is unique to each patient.

Discussion: The themes together can be considered prerequisites for good palliative home care. If nurses fail to be sensitive and perceptive in encounters with dying patients, good palliative home care cannot be achieved. Ethical sensitivity and perceptiveness can also be considered a part of nurses' ethical competence. Conclusion: Patients' dignity can be preserved through ethical sensitivity and perceptiveness, which is fundamental for good palliative care. Co-creation from patients' perspectives should be the focus of future research.
\end{abstract}

\section{Keywords}

Caring, co-creation, hermeneutics, interviews, nurses, palliative care, thematic analysis 


\section{Introduction}

Older populations throughout the world are expanding, and subsequently home care as a form of care will increase as well. ${ }^{1}$ According to the World Health Organization, ${ }^{2}$ to enable qualitative care it is vital that healthcare services support patients who wish to receive end-of-life care at home. To ensure care quality, athome caregivers must establish a good caring relationship with patients and patients' relatives. A good caring relationship enables the emergence of patients' sensitive needs and allows caregivers to take patients' own perspectives into account in an ethical manner. The co-creation of patients' goals in palliative home care can be considered to constitute good-quality care. ${ }^{3}$

\section{Background}

As a concept, co-creation can be defined in palliative home care as the joint creation of vital goals for patients through the process of sharing knowledge in a caring manner. ${ }^{3}$ When sharing knowledge all "team members" involved in the caring relationship, including nurses, patients and patients' relatives, should contribute so that the patient's goals can emerge. ${ }^{3,4}$ The concept of palliative care has been used interchangeably with the terms end-of-life care, hospice care and terminal care. ${ }^{5}$ The term home care or palliative home care' refers to home care delivered by a professional team, providing 24-h service with access to inpatient care in a hospital ward. ${ }^{6,7}$ Usually registered nurses (RNs), physicians, medical social worker, physiotherapist and occupational therapist, work in the team with access to a dietician and sometimes a chaplain and can be described as the Nordic context within this area. To create stable and caring nurse-patient relationships in home care, nurses must perceive patients as being experts on how to live their lives and harness patients' expertise and experience through dialogues. ${ }^{1}$ Co-creation in nursing has also been defined as a deep, thoughtful, co-created nursing process, in which nurses heed patients, spend time with them and engage them in personal reflection. ${ }^{8}$ When co-creating through end-of-life communication in palliative care, nurses should establish context, acknowledge patients through attentive listening, make it safe for patients to die, plan care goals and be honest. ${ }^{9}$ Nurses, patients and patients' relatives all possess expertise and can therefore together create the best possible care goals to be vital. ${ }^{9}$

In order to provide relevant services to home-dwelling patients during the palliative phase, staff changes should be avoided and nurses' palliative care skills developed. ${ }^{10}$ If unique, person-centered care is to be realized, co-creation and flexibility are vital. ${ }^{10}$ Home care is jointly shaped by health professionals, patients and patients' families and is based on a trusting relationship. ${ }^{11}$ Knowing the other through a co-creating process is fundamental to developing a sense of familiarity, including the establishment of a mutual, trusting relationship through which worries could be expressed without tension arising. Learning from others, that is nurses' familiarization with each patient's health, personality and life situation, can ease nurses' assessment of and decision-making in regard to the patient's needs. ${ }^{11}$ Nurses" "being there" for the patient involves nurses being completely present, physically and mentally, and interested in being involved with the patient. ${ }^{11}$

To "be there" for a patient requires ethical sensitivity, through which nurses strive to understand and compassionately respond to those in their care. ${ }^{12}$ In caring science, ethical sensitivity was initially described as the first step in the decision-making process in professional practice, meaning recognizing and interpreting the ethical dimension of each care situation. ${ }^{13}$ Many researchers have investigated the concept, with ethical sensitivity being defined as a caring response or intuition about others' feelings or to be moved by or identify with others' distress. ${ }^{14-16}$ Ethical sensitivity has also been perceived as an intuition about others' comfort and well-being, a component of moral care ${ }^{11,16}$ and an of how diverse courses of action may affect others. ${ }^{14,16,17}$ Rest $^{18}$ as a pioneer in the development of ethical sensitivity described four major kinds of psychological processes in the Four Component Model that "must have occurred for moral behavior to 
occur" (p. 3), and created a model from these. The first component in Rest's model, moral sensitivity, relates to the ability to identify the significant aspects of a moral dilemma. The second component, moral judgment, involves a person choosing a moral outcome over an immoral one; a person may have an awareness of an issue (moral sensitivity) but nonetheless choose to act without morals. Narvaez ${ }^{19}$ found that moral sensitivity consists of two components, moral perception and moral interpretation. According to Narvaez, ${ }^{19}$ perception relates to a semi-conscious or unconscious sense that a moral issue exists and this sense incorporates elements of attention, and interpretation relates to the conscious realization that a moral situation exists and a judgment is required. According to Vetlesen, ${ }^{20}$ attentiveness is a major part of perception, and before coming to a moral judgment, moral sensitivity may be used. The third component in Rest's model, moral motivation, is related to the ability to choose between moral and non-moral values and commit to the moral value. Problems can arise in relation to moral motivation if a person is not motivated to place moral values above other values, for example, disregard personal or organizational values. The fourth component, moral character, relates to a person's ability to take moral action thanks to his or her profound commitment to moral values above personal ones; it takes courage or "ego strength" for a person to stand firm in a commitment.

Ethical awareness is the initial phase in moral action and, for example, in nursing, it involves identifying the ethical implications of all nursing actions. ${ }^{21}$ Such involves noticing the risk that nursing actions could be incongruent with the goals of nursing and, thus, violate ethical principles. ${ }^{21}$ Ideally, such awareness leads nurses to engage in the most ethically acceptable manner. Weaver et al. ${ }^{22}$ defined ethical sensitivity as,

the capacity to decide with intelligence and compassion, given uncertainty in a care situation, drawing as needed on a critical understanding of codes for ethical conduct, clinical experience, academic leaning and self-knowledge, with an additional ability to anticipate consequences and the courage to act. (p. 610)

Weaver et al. ${ }^{22}$ further described ethical sensitivity as a type of "practical wisdom" (p. 615), meaning that a central feature of ethical sensitivity is the capacity for decision-making in uncertain professional practice. Other researchers consider ethical sensitivity to be a sense of obligation or responsibility toward the other. ${ }^{14,16}$ Petersen ${ }^{23}$ described moral sensitivity as a part of the ethical problem-solving process and the learning cycle of moral competence, in which moral sensitivity leads to ethical reflection, that is interpretation, which in turn leads to moral judgment and moral behavior. Jagger ${ }^{24}$ found aspects such as perception and interpretation to be components of the complex concept that is ethical sensitivity. Vetlesen ${ }^{20}$ maintained that in regard to the ability to interpret, in relation to ethical sensitivity, an ethical issue becomes a requirement. Dellaportas et al. ${ }^{25}$ described ethical sensitivity as, “ . . the way people initially encode an ethical situation and the consequences that a person's actions might have on others" (p. 70). Dellaportas et al. ${ }^{25}$ found that ethical and sensitivity prevents unethical behavior. A person with lower ethical sensitivity is more likely to ignore the ethical issues present, in comparison to persons with higher levels of ethical sensitivity. ${ }^{26}$ Ethical sensitivity can consequently be considered a fundamental component of ethical action, ${ }^{15}$ meaning practice actions in nursing. ${ }^{27}$

In a systematic review, Poikkeus et al. ${ }^{28}$ investigated nurses' ethical competence and found that it includes ethical sensitivity, ethical decision-making, ethical knowledge and ethical reflection. In research, the concept ethical sensitivity has been used synonymously with moral sensitivity, clinical sensitivity, moral perception, ethical perception, clinical perception, ethical intuition and moral or ethical sensibility. ${ }^{13}$ Investigating the foundation of ethical sensitivity, Nortvedt ${ }^{29}$ established an understanding of the concept through subjectivity, vulnerability and receptivity, finding that if caregivers are to understand the suffering and vulnerability of the other human beings in their care, they should reflect on the ethical perspectives that they are responsible for. 
Milliken ${ }^{27}$ highlighted that nursing actions should be rooted in ethical codes for nurses, in the form of professional ethical standards, since ethically incongruent care may be the consequence of diminished or absent ethical sensitivity, which is contradictory to the professional responsibilities of nursing and cocreation. Robichaux ${ }^{17}$ noted that recognition of an ethical situation must exist before reasoning or action can occur. In other words, nurses need an understanding of the ethical situation and the sensitivity to discover and interpret verbal and non-verbal behaviors in to order to identify patients' needs. ${ }^{30}$ Ethical sensitivity has been further defined as moral perception, affectivity and dividing loyalties. ${ }^{22}$ Ethical sensitivity is considered to facilitate the recognition, understanding, upgrading and evaluation of a situation. ${ }^{22}$ Grace $^{31}$ stated that attention and sensitivity are vital for developing ethical competence. Benner ${ }^{32}$ found that clinical judgment and ethical sensitivity are closely related to one another and should therefore not be separated; these determine what good is at stake for the patient and what to do in different clinical contexts. ${ }^{33}$ According to Robichaux, ${ }^{17}$ the linking element between ethical judgment and action is ethical motivation, which involves a longing to act and live in a manner consistent with one's moral values.

Ethical sensitivity is integral to the deliverance of high-quality care. ${ }^{22}$ Perceptiveness, knowledge and the will to do good may also enhance the caring relationship in palliative home care. ${ }^{34}$ From a caring science perspective, ethical and good caring encounters are based on caregivers' ability to see each patient as a unique human being and preserve the patient's dignity in order to alleviate suffering. ${ }^{35}$ In home care and especially end-of-life care, co-creation and ethical sensitivity are important tools for alleviating patients' suffering and enhancing patient's well-being through quality of life. ${ }^{3,4}$ Harstäde et al. ${ }^{36}$ emphasized perceptiveness as a core approach in palliative care, when dignity-conserving care action through co-creating is sought. A recently published theory on co-creation highlighted the special skills nurses need for end-of-life home care, such as being open to the more complex processes in palliative home care. ${ }^{3}$ As seen in earlier research mentioned above, ethical sensitivity is a concept that, while central for patients in every care context, become even more crucial in the context of palliative home care, where the preservation of the vulnerable and dying patient's dignity is essential. Therefore, building on the previous research on this subject, and the fact that no studies were found on the ethical aspects of the phenomenon of co-creation in palliative home care from a caring science view, we sought explore this perspective further.

\section{Aims}

The aim of this study was to explore nurses' experiences of caring encounters and co-creation in palliative home care from an ethical perspective.

\section{Theoretical perspective}

The fundamental condition for caring is found in the caritas motive, which entails a spontaneous willingness to take responsibility and sacrifice something for the other in love. ${ }^{35,37}$ The dignity of the human being is at the center of everything in caritative theory. ${ }^{37}$ The human being yearns to belong to a communion but simultaneously wishes to be unique. According to the ontological perspective of caring science, health is understood as a "becoming," a movement toward deeper wholeness and holiness. The world of caring is characterized by interest and true engagement, through which the patient is understood, participates and is taken seriously. ${ }^{38}$ Caritative care can enable patients' becoming in health and help them experience harmony and meaning in life. In the caring communion, the nurse and the patient are involved and work together, and both are involved in the care given. ${ }^{35}$ The patient strives for a sense of value as a human being in all contexts. ${ }^{39}$ Eriksson $^{35}$ indicated that by participating in a communion with others and oneself, the patient can find ways to alleviate his or her suffering. Helping another human being become a whole person is an expression for the true human being and caring's innermost core. 
Table I. Study participants.

\begin{tabular}{|c|c|c|c|c|c|c|c|c|c|c|c|c|}
\hline Participant number & $\mathrm{I}$ & 2 & 3 & 4 & 5 & 6 & 7 & 8 & 9 & 10 & II & 12 \\
\hline Age & 64 & 52 & 56 & 46 & 23 & 49 & 62 & 39 & 52 & 50 & 45 & 52 \\
\hline $\begin{array}{l}\text { Gender: } \\
\quad F=\text { female } \\
M=\text { male }\end{array}$ & $\mathrm{F}$ & $\mathrm{F}$ & $M$ & $\mathrm{~F}$ & $\mathrm{~F}$ & $\mathrm{~F}$ & $\mathrm{~F}$ & $\mathrm{~F}$ & $\mathrm{~F}$ & $\mathrm{~F}$ & $\mathrm{~F}$ & $\mathrm{~F}$ \\
\hline $\begin{array}{l}\text { Work experience: years as a nurse } \\
\text { Current occupation: private home } \\
\text { care organization = priv. } \\
\text { Public home care organization = } \\
\text { pub. }\end{array}$ & $\begin{array}{c}43 \\
\text { priv. }\end{array}$ & $\begin{array}{l}13 \\
\text { priv. }\end{array}$ & $\begin{array}{c}33 \\
\text { pub. }\end{array}$ & $\begin{array}{l}26 \\
\text { pub. }\end{array}$ & $\begin{array}{c}\text { I } \\
\text { pub. }\end{array}$ & $\begin{array}{c}25 \\
\text { pub. }\end{array}$ & $\begin{array}{c}27 \\
\text { pub. }\end{array}$ & $\begin{array}{l}18 \\
\text { pub. }\end{array}$ & $\begin{array}{c}34 \\
\text { pub. }\end{array}$ & $\begin{array}{c}30 \\
\text { priv. }\end{array}$ & $\begin{array}{c}22 \\
\text { pub. }\end{array}$ & $\begin{array}{l}31 \\
\text { pub. and } \\
\text { clinical ward }\end{array}$ \\
\hline
\end{tabular}

\section{Methodological aspects}

This study was inspired by a hermeneutical approach in accordance with Gadamer. ${ }^{40,41}$ The data material consisted of texts from in-depth interviews with 12 nurses. The method was inspired by thematic analysis. ${ }^{42}$

\section{Data material and data collection}

Twelve Finnish nurses (age range 23-64) were interviewed about their experiences of co-creation and ethical sensitivity in the home care context. The participants all shared the same socioeconomic background but came from both urban and rural areas in a bilingual area of Ostrobothnia, Finland (see Table 1). The participants were recruited in collaboration with head nurses from home care contexts in two public care organizations and a private home care organization, all three in Ostrobothnia. All of the participants worked in home care and cared for terminally ill and dying patients. They had different experiences in relation to palliative care. Seven participants had been trained in palliative care, while others, were not explicitly trained in palliative care yet still had experience of providing end-of-life care. The participants' responses varied depending on the length of time they had worked as a nurse and, specifically, as a palliative care home nurse. The in-depth interviews lasted between 60 and 90 minutes and took place in the various aforementioned home care contexts or at the university where the first researcher worked. An interview guide was used, which included a focus on how nurses care for a patient in end-of-life home care in a cocreative way and how they create opportunities for the patient by working together with the patient and his or her relatives. The guide also included a focus on how nurses could support a patient's wishes and needs in different situations, such as sensitive situations. The guide allowed for the creation of follow-up questions in response to the participants' statements. That an ethical perspective was included in this study facilitated a focus on the search for sensitivity in the palliative home care context, both through the interview questions and during analysis. The researchers had different backgrounds. The second researcher had extensive experience of working as a nurse in the home care context while the first researcher had more experience of working as a nurse on clinical wards with older people and as a public health nurse.

\section{Thematic analysis}

The data material was analyzed using thematic analysis inspired by Braun and Clarke, ${ }^{42}$ which meant that data familiarization was first performed, by reading and re-reading the data. Thereafter, the researchers coded the data in order to capture a semantic reading of it and to find themes of meaningful patterns with relevance to the aim of the study. Finally, the researchers reviewed the themes in an iterative process where 
both researchers analyzed the relationships between the themes back and forth until finally an informative name for each theme was created.

In a spirit of hermeneutics and inspired by Gadamer, ${ }^{40,41}$ the interpretation was a movement between the whole-parts-whole and between interpretation and understanding, and openness was used in the reading and analysis of the data material. The researchers approached the material with an alert watchfulness. Moreover, the hermeneutical approach entailed that the researchers read the data material with an openness while also interpreting "between the lines," in order to uncover any hidden meaning. During the course of the interpretation, the researchers took care to articulate and repeat the preunderstanding, thus facilitating that it could be mastered and preventing it from guiding the interpretation. To ensure mastery of their pre-understanding, the researchers were careful to constantly formulate it during the interpretation and thereby prevent it from steering the interpretation. When the preunderstanding was challenged during reading, the preunderstanding and substance of the material were slowly invited into the scientific dialogue. A continuous and critical reflection of the preunderstanding and the text as a whole occurred. Through a movement between the whole-part-whole and between the interpretation and understanding, the analysis process was iterative; the researchers interpreted and formed the findings from their horizon of understanding in repeating rounds and through reflections against the whole in order to reach a new understanding.

\section{Ethical considerations}

The nurses selected for participation were contacted personally by one of the researchers through e-mail and were given both oral and written information about the study purpose, confidentiality, withdrawal of consent and intent to publish. Informed consent regarding participation in the study and the storage and handling of data for research purposes was sought from the participants. The study was approved by the organizations where the participants worked and ethically conducted in accordance with the guidelines delineated by The Finnish National Advisory Board on Research Ethics. ${ }^{43}$ The first researcher transcribed all of the interviews.

\section{Findings}

One overall theme, one main theme and four subthemes emerged. The overall interpretation can be conceptualized as "Caring with ethical sensitivity and perceptiveness, through balancing nursing actions in the moment." The main theme was "Co-creation as ethical sensitivity and perceptiveness in home care encounters." The main theme and subthemes are discussed below (see Figure 1).

\section{The overall interpretation}

The overall interpretation can be conceptualized as "Caring with ethical sensitivity and perceptiveness, through balancing nursing actions in the moment." It is all about the nurses' ability to be perceptive and can be considered a prerequisite for achieving good palliative home care. Ethical sensitivity is knowledge based on experience within the nurse and perceptiveness is the nurse's ability to be open to the external situation and the patients' needs. The aspect of time, consequently, is of importance because each patient's need for time is unique and the co-creation of needs in end of life was seen as taking more time, due to the ethical sensitivity of the situation in home care. The subthemes together can also be considered prerequisites for good palliative home care, but these cannot be realized if nurses lack the ability or fail to be perceptive in caring encounters. When presenting the themes in figure form, the aspect of time is symbolized by arrows that accordingly differ in length. 


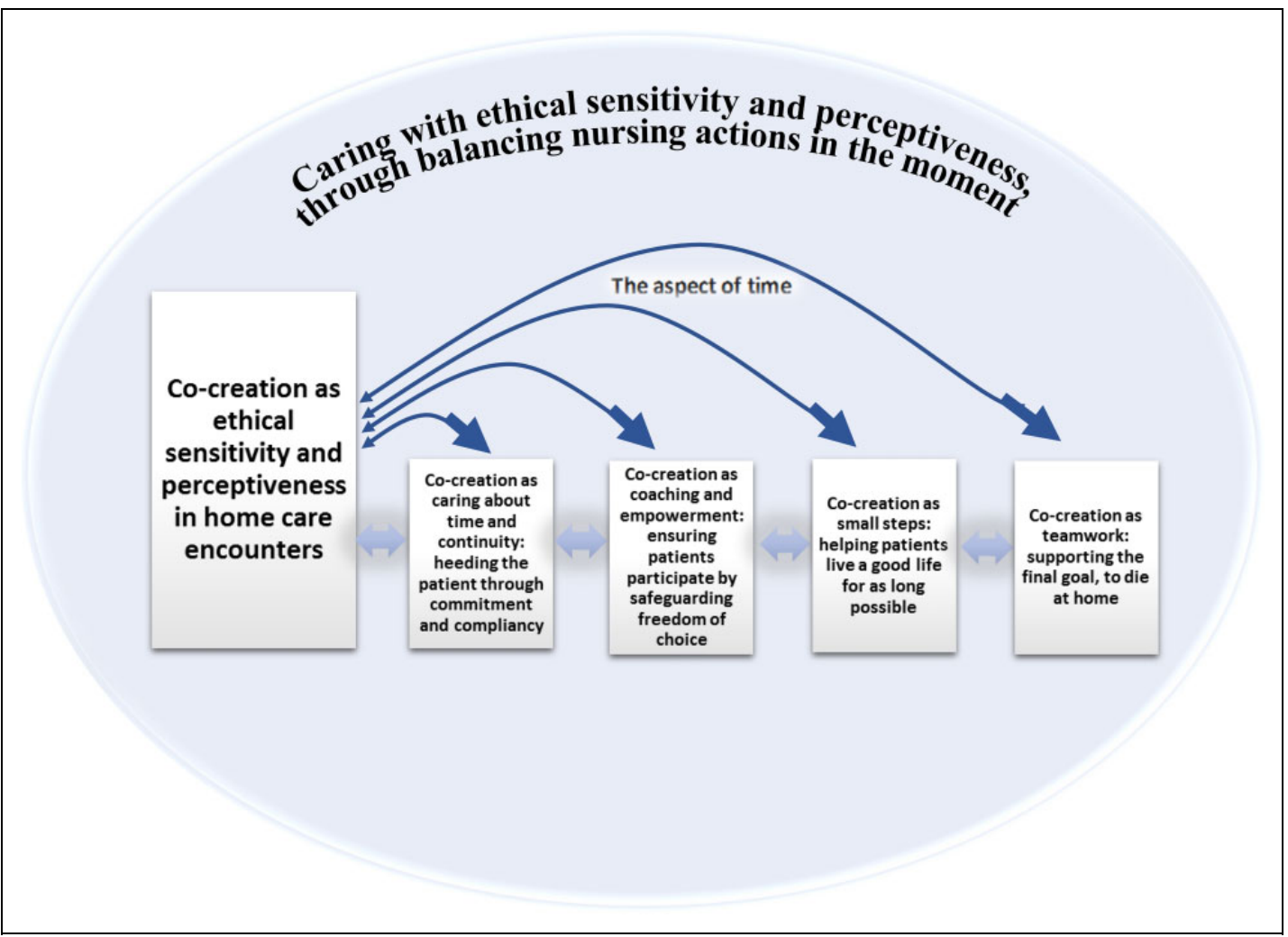

Figure I Study findings: The overall theme as "Caring as ethical sensitivity and perceptiveness, through balancing nursing actions in the moment".

\section{Co-creation as ethical sensitivity and perceptiveness in home care encounters}

The main theme concerned co-creation as ethical sensitivity and perceptiveness in palliative home care encounters. In order to understand patients' wishes, nurses need to have ethical sensitivity which is a knowledge based experience within the nurse and he or she needs the ability to be perceptive, meaning to in co-creation be open to the external situation and the patients' needs, what they say or leave unsaid in the caring situation. The main theme is also related to all co-creation processes and illuminates the ethically sensitive balancing act that occurs in the care process and which takes time:

You hear which questions the patients ask and where is he right now ... you hear and see that ...even those unasked questions [tell you] of course a lot. And then you must of course be very sensitive also, and think first whether it is appropriate to say something or not ...? (P6)

Through ethical sensitivity in palliative care, nurses can understand how far a patient has come into his or her acceptance of their illness, which enables a unique encounter. Co-creation is a process in which the nurse at that moment is perceptive of what is happening and at the same time leans toward its foundation and ability to handle ethical sensitivity:

But it is important that you sit down when you discuss and have a soft tone and that it feels relaxed and ...then you ask [carefully], 'how is it going and how are you managing here at home?' (P11) 
Co-creation entails nurses listening to the patient when he or she confronts and asks a nurse to take a step back and not force an issue. The caring relationship can develop in a good manner if nurses can respectfully balance nursing actions in the moment and adapt to patients' care wishes. If, despite an obvious need for support, a patient is silent and does not indicate a need for contact, the nurse's ethical sensitivity as knowledge based experience can provide clues regarding what is considered best solution in a particular situation. The nurses ability to be perceptive involves being open to the situation and thereby being willing to participate in co-creation and through deep knowing and experience understand what is particularly important:

... and then it becomes of course this... [the patient says during the phone conversation] 'No, it is not really good to be sure,' and then I usually ask, 'Do you want me to come?' and then there can come a cautious answer: 'Yes, I want that no doubt...' and then I have understood that the patient will not either [call again] in the future ... but now it is me that should be the active [one]. (P1)

\section{Co-creation as caring about time and continuity: heeding the patient through commitment and compliancy}

Time and continuity were seen as being important for co-creation in palliative home care in this subtheme. Nurses and patients wander a path together, which takes time, and patients experience a sense of security if they have the same nurse over a longer period of time. Continuity in the caring relationship entails nurses knowing their patients and their unique histories:

... and [when the same nurse spends a lot of time with the patient] ... that is when you create the security and you notice of course how they attach themselves ... that it is me ... it is just me ... and then it is not like then when there [were] many [different nurses] ... (P1)

Ethical sensitivity and perceptiveness is needed in palliative home care, and nurses should reserve a lot of time in order to gain a sense of and map how the patient feels and what he or she is capable of, and they should find out how the patient's relatives should be involved:

I often simultaneously include the relatives in the meeting. And if there is the opportunity then we gladly speak with the relatives separately, but that opportunity is not always given... [if] there is something that the relatives want to discuss then I usually say that they can call or else I can come separately [just to discuss with them]. Time is the determinate [here] ...that I go [there], sit down, here I am now and am here for you. (P7)

Ethical sensitivity and perceptiveness is needed if trust in the caring relationship is to be developed. Nurses must act in a respectful manner in the patient's home and discuss matters with the patient, such as when the next visit is to occur. Trust is gradually built thorough continuity, and ultimately this is a question of nurses' compliancy with and balancing of the patients' needs and wishes. For trust to develop, it is sometimes necessary for patients to experience that specific care measures have been successful because of co-creation:

I had a male patient with cancer...you noticed about him, without a doubt, that, "here you just do what you should and nothing more.' But then one morning he called... and then I said, 'try to take that medicine when you are up and on the toilet during the night'...Then he called and said, 'Oh, the medicine was so good, I became so good!.' And in this way confidence and trust in the caring relationship gradually started to grow... 


\section{Co-creation as coaching and empowerment: ensuring patients participate by safeguarding freedom of choice}

Coaching and empowering patients through co-creation enabled patient participation through freedom of choice, which emanates from nurses' ethical sensitivity as the nurse's inner knowledge-based experience. Getting to know the human being "behind" the patient is the foundation for cooperation and co-creation, through which the best possible outcomes for patients can be realized. In the co-creative process, nurses teach and guide patients in a "coach-like" manner:

And when it comes to different care procedures then I always tell the patient about what I do and ... how I do and when I have [finished] then I say [to the patient] that now it is up to you what the end result is ... they become involved so that they do not feel left out of the process... You also teach them the whole time ... you explain and you tell ... (P9)

Nurses' coaching of patients through co-creation can help activate patients so that the patients begin to perform care procedures by themselves. By asking the patient questions about how he or she experiences things, nurses can balance activities and, as a coach, help the patient participate in the care relationship and enable the patient's freedom of choice. Balancing sometimes implies that nurses must "take a step back" if they are not sufficiently in tune with the pace that the patient is keeping. Co-creation is a balancing act for all involved - nurses, patients, patients' relatives - with the goal being empowerment of the patient:

I said that she can decide for herself but I think [as a nurse you] should try ... and first we can try together and then you see [whether] it works or does not work... you encourage and instill confidence ... and you absolutely do not force ... And absolutely not with a domineering tone ... you cannot trample on the patient's integrity, but [instead] you must be sensitive. (P10)

Nurses can also try to help patients focus on "the positive" through humor, which is a form of empowerment that can facilitate the realization of care goals:

Yes, we without a doubt have [humor] every day ... it is vitally important sometimes ... Also in the [face of death] a little humor lightens the atmosphere and you can also more easily get [things such as care measures] done... But it is on their terms. You see afterward how they react, if they rise to the occasion or not ... (P10)

\section{Co-creation as small steps: helping patients live a good life for as long as possible}

When nurses realize co-creation in a caring manner they use their perceptiveness and ethical sensitivity to gradually, step by small step, work together with the patient and the patients' relatives to help the patient live as well as he or she can for the duration of his or her life. Goals are set and realized in a step-by-step process, where through co-creation of partial goals are determined and achieved, all in accordance with the patient's wishes, a process that takes time:

If I think that the patient has understood something in the wrong way... then I usually present smaller facts so that they themselves eventually have [an] aha experience... [if] you notice that progress is not being made then you say [to the patient] that you do not need to decide anything now instead you can think about it ... that you give time and exude calmness are very important.... It grows on its own. Many situations arise quickly and the patient cannot take everything in ... you of course see that ... when they themselves are ready. And that you yourself listen, too, when they themselves start to ask those questions. (P12) 
In co-creation in palliative home care, nurses must give patients suggestions for certain partial goals, that is, "plant a seed" that will motivate the patients. Nurses can provide patients with information and tell them about the various paths and possibilities available. The participants here noted that a feeling of shame can underlie why some patients choose not to use assistive devices such as a wheelchair. Nurses' ethical sensitivity, perceptiveness and encouragement through a balancing act can be employed to help, step-bystep, introduce an idea and then allow the patient to adjust to the idea or situation:

Yes, I think so. Because I usually say think how nice it would be to go outside now when it is such beautiful weather... But then they say, 'Yes, but you of course cannot sit in a wheelchair...' But last week I had a couple who said that they have begun to think about this and perhaps it no doubt could be good [to use a wheelchair] ... and there I had sown a seed earlier ... that had begun to grow... (P11)

Co-creation in palliative home care also pertains to promoting the patient's well-being for as long as the patient is alive. Living until one dies can relate to being allowed to decide how one wants to die, as one participant noted, "To be allowed to have your cat in your lap when [your] life ends can mean a lot" (P7). Through co-creation, nurses can balance nursing actions in the moment and fulfill such wishes, which provides patients with a sense of well-being and the strength to face death.

\section{Co-creation as teamwork: supporting the final goal, to die at home}

Quality of life at end of life can be improved when everyone — nurses, patients, patients' relatives - join together and work as a close-knit team in the home. The patient's relatives and the home itself play a big role. The participants perceived patients' relatives as a tremendous resource and maintained that relatives, as part of the "care team," should be included in discussions about end of life: as long as their inclusion is in line with the patient's wishes. Patients' relatives should be given a voice in matters, but their wishes should not supersede the patient's wishes. Nurses through their ethical sensitivity and understanding of co-creation have the opportunity to balance nursing actions in the moment and support patients in their final goal, to die at home:

There was a young mother who was 27 years old. Who was terminally ill ... It was [a] young family with [a] little child... And there were also many of the [family's] closest as well ... you became a care team with them all. Not everyone was there the entire time, but they followed the situation... She lived about a halfyear. Her wish was to be at home and live with her family during the last [part] of her life. And she got to. (P7)

The home itself is the patient's "territory," so nurses should use their ethical sensitivity and perceptiveness to navigate there. Co-creation is also needed, to balance the care measures undertaken there. Cocreation includes listening to the patient in regard to his or her final wishes and desires, which often relate to the patient wanting to spend his or her last time on earth at home together with loved ones. Making this possible can improve and/or sustain the patient's quality of life and sense of security, up until the moment he or she dies:

Now in this case then ... [a young and dying patient] said it. He said [it] straight out, and he wept from joy when he was so grateful.... And he did not live long... a few months ... but he got to live until he died [in his own home]. (P7)

\section{Discussion}

The aim of this study was to explore nurses' experiences of caring encounters and co-creation in palliative home care from an ethical perspective. In this study, we found that co-creation and caring encounters are based on time, ethical sensitivity and perceptiveness, which can be considered a part of nurses' ethical 
competence. We found that the need for ethical sensitivity as a knowledge-based experience within the nurse and perceptiveness as the ability to be open to all aspects of the patients situation is essential, particularly in palliative home care and in co-creation. ${ }^{34,44}$ Jagger $^{25}$ noted that ethical sensitivity is a complex concept, in which the components perception and interpretation are included. Southall, ${ }^{45}$ among other researchers, noted that attentiveness was also crucial ${ }^{8}$ and, according to Vetlesen, ${ }^{20}$ attentiveness is an important part of perception. Attentiveness can be compared to perceptiveness, which according to Harstäde et al. ${ }^{36}$ is a core ability for nurses when striving for care action that preserves dignity in palliative care. Weaver and Morse ${ }^{12}$ noted that the use of the term ethical sensitivity implies that nurses strive to understand and compassionately respond to patients. Rest ${ }^{18}$ focused on moral competence and presented components of moral sensitivity: the first component was moral sensitivity, which related to the ability to identify the significant aspects of a moral dilemma and the second component was moral judgment, involving a person choosing a moral outcome over an immoral one. The third component in Rest's model was moral motivation which involves an ability to choose between moral av non-moral values yet commit to the moral value. The fourth component, moral character concerns a person's ability to take moral action and stand firm in a commitment, meaning to chose moral values for example above personal ones.

Co-creation in palliative home care means according to this study to genuinely be willing to strive to understand the patient through ethical sensitivity and be attentive in order to perceive patients' expressed, unexpressed or hidden needs and desires. This requires that sufficient time be spent with the patient to, using compliancy, enable nurses to follow the patient and through small steps forward reach goals in line with the result of this study. Other researchers have found that nursing presence is a reciprocal act of mutuality driven by the need and willingness of the patient in congruence with the nurse's authentic commitment to be fully attentive ${ }^{38}$ totally present, interested and involved. ${ }^{11}$ Nortvedt ${ }^{29}$ emphasized that nurses' ability to be fully aware of patients' vulnerability and subjectivity is essential for nurses' ethical sensibility in the care of the other. As Eriksson ${ }^{35}$ noted, from a caring perspective, participation and encountering and unconditionally serving the patient so that his or her uniqueness and dignity as a human being is preserved are important. ${ }^{30}$ We furthermore found that when nurses act like a coach, by demonstrating ethical sensitivity and perceptiveness to the patient's needs and emanating from a caring understanding, ${ }^{35,37}$ this can be interpreted as nurses simultaneously maintaining patients' dignity. ${ }^{8}$ This can be compared to Benzein et al., who found that caregivers in co-creation must view patients as experts on how to lead their lives and that patients should be allowed to apply their expertise in nurse-patient dialogues.

Using their ethical sensitivity and perceptiveness, nurses can demonstrate through co-creation in palliative home care that they are capable of balancing their nursing actions in the moment and of taking a respectful "step back" in order to allow patients to control matters, in those cases when nurses move forward too quickly and do not sufficiently follow the patient's pace. ${ }^{11}$ This study showed that nurses heed their patients by caring about time and continuity and through commitment and compliancy: both nurse and patient together taking small steps forward. Ersoy and Göz ${ }^{33}$ also found that ethical sensitivity is needed in order to detect ethical issues in a caring situation, seen here as a nurse's ethical sensitivity and perceptiveness. Compliancy involves nurses planting small seeds of thought that begin to grow in the patient's mind and which awaken the patient's desire to accept matters, for example, use a new assistive device or try a new care method whereby suffering can be alleviated ${ }^{31}$ and well-being and quality of life promoted. This is in line with theory of a co-creative process, ${ }^{3}$ in which the co-creative process includes main-, sub- and microprocesses, with a working phase in the middle where patients' thoughts are shaped and reshaped over time, which requires giving patients time to adjust the process to their own pace. Skills that nurses need in order to create a care partnership include listening with intent and the ability to "slow down" and confirm a patient's emotions, ${ }^{11}$ that is, the ability to mind the subjectivity of the other person. ${ }^{29}$ In our study, we found that nurses through co-creation should be active partners who, through ethical sensitivity and perceptiveness, gain a sense of what the patient needs ${ }^{13,14,18,33}$ and who through a balancing act form caring activities 
that in the moment match the patients' needs and wishes. It is also well known that dying patients can pendulate between hope and despair, between the desire to live and the will to die. In a delicate sensitive moment, the patient can desperately hold on to a false hope, to mentally survive another day. If the nurse at that moment in time fails to use ethical sensitivity and his or her ability to be perceptive, the consequence can be a violation of the patient's dignity and well-being. ${ }^{35}$

In our study, time was seen as being essential for co-creation and the co-creation and meeting the patients' needs at end of life was interpreted as taking more time, due to the ethical sensitivity of the situation in home care. Griffiths ${ }^{8}$ also mentioned time as a cornerstone for co-creation, finding that nurses' observations of the small details of a patient's behavior allows nurses entry into the patient's world, which can only occur when time is spent with one another. This can be compared to Lindahl et al., ${ }^{11}$ who noted that creating stable relationships where those involved see and treat each other as individuals is the key for establishing professional friendships. Based on our study, one can ask whether the time for and sensitivity to patients and patients' relatives' need for time and space are prerequisites for nurses' provision of good quality palliative home care? Still, care that takes time is often considered unproductive care. ${ }^{8}$ The lack of time in care may subsequently impair nurses' ability to be perceptive, as perceptiveness in palliative home care requires time. ${ }^{34}$ The question remains whether nurses can maintain their ethical sensitivity and perceptiveness in care situations when time is lacking or if the nurse due to the stress caused by limited time with each patient experiences deprivation in his or her moral motivation and moral character as described by Rest. ${ }^{18}$ If the nurse's moral motivation and moral character suffers due to time limits in her work, this may interfere with her strength of choosing moral actions above personal ones. ${ }^{18}$ Hence, time is may be seen as crucial for enabling nurses to use their abilities of moral actions. We found that time was essential not only for nurses to gain a sense of the patient, but also in reverse for patients to know or gain a sense of the nurse in order to establish a good and profound relationship. Knowing the other creates a sense of security and safety, and can be compared to "deep nursing," 8 a co-creative process realized by both the nurse and patient, who understand the other and jointly strive toward a mutual goal. We found that ethical sensitivity and perceptiveness in co-creation enable a profound caring relationship and that having a close-knit "care team" is preferable in palliative care, because this makes the patient feel more secure. ${ }^{10}$

Empowerment and ensuring that patients participate in their own care by safeguarding freedom of choice was seen as central to co-creation in palliative home care; these facilitate nurses in helping patients achieve essential goals, which is comparable to the realization of person-centered care. Through coaching, various alternatives can be shown to patients, but it is nevertheless the patient himself/herself who ultimately chooses which path to take, which can be enabled through nurses' ethical sensitivity and perceptiveness and by balancing nursing actions in the moment. Milliken ${ }^{27}$ also highlighted that nurses' actions should be rooted in ethical codes for nurses, which can also be compared to Griffiths ${ }^{8}$ who maintained that, generally speaking, in nursing the "power" should be given to the patient and nurses should negotiate care and support plans with patients. As interpreted in this study, empowerment in palliative home care can pertain to empowering patients to complete goals that are important to them. We also found that in palliative care, nurses' ethical sensitivity is essential during a patient's end of life, especially in regard to the ability of being perceptive, meaning being open to others' vulnerability, subjective needs, and desires ${ }^{29}$ in the pursuit of preserving dignity and alleviating suffering. Nurses should use their ethical sensitivity and perceptiveness in co-creation to balance the inclusion of patients' relatives so that their voices are heard, but without foregoing the patient's wishes.

\section{Strengths and limitations}

If a different participant group were seen, for example, more male participants, the results might differ to some extent and this could therefore constitute a source of bias limiting the generalizability and 
comparability of the findings. Only interviews were used, thus in the future observation studies should be undertaken. Still, the study is trustworthy and included a nuanced depiction of the subject matter, and the interviews yielded rich data on nurse's experiences of ethical caring in home care through co-creation. Qualitative rigor was enabled by both researchers taking part in the data analysis and engaging in an iterative process, where both researchers individually interpreted and formed the findings from their horizon of understanding in repeating rounds and through reflections against the whole in order to reach a new understanding. This study is defensible from an ethical perspective, because the nurses' experiences might possibly help others develop deeper thoughts about co-creation in caring in palliative home care.

\section{Conclusion}

Understanding "Caring with ethical sensitivity and perceptiveness, through balancing nursing actions in the moment," can support nurses in understanding co-creation in a deeper sense and acting as the patients' advocates, which is essential in caring for patients in palliative home care and at end of life. Time is of great importance and has implications for clinical practice in this context. Co-creation from patients' perspectives in palliative home care with regard to ethical sensitivity, perceptiveness and time should be the focus of future research.

\section{Conflict of interest}

The author(s) declared no potential conflicts of interest with respect to the research, authorship, and/or publication of this article.

\section{Funding}

The author(s) received no financial support for the research, authorship, and/or publication of this article.

\section{ORCID iD}

Jessica Hemberg (D) https://orcid.org/0000-0002-0829-8249

\section{References}

1. Benzein EG, Hagberg M and Saveman B-I. 'Being appropriately unusual': a challenge for nurses in health-promoting conversations with families. Nurs Inq 2008; 15(2): 106-115.

2. World Health Organization. Palliative care for older people: better practices. Copenhagen: WHO Regional Office for Europe, 2011.

3. Bergdahl E, Ternestedt B-M, Berterö C and Andershed A. The theory of a co-creative process in advanced palliative home care nursing encounters: A qualitative deductive approach over time. Nursing open, 2019; 6: 175-188.

4. Bergdahl E, Benzein E, Ternestedt B-M, Elmberger E and Andershed B. Co-creating possibilities for patients in palliative care to reach vital goals - a multiple case study of home-care nursing encounters. Nursing Inquiry, 2013; 20(4): 341-351.

5. Izumi S, Nagae H, Sakurai C, et al. Defining end-of-life care from perspectives of nursing ethics. Nurs Ethics 2012; 19(5): 608-618.

6. Ministry of Social Affairs and Health. Good end-of-life care in Finland, https://julkaisut.valtioneuvosto.fi/bit stream/handle/10024/71949/URN\%3ANBN\%3Afi-fe201504225791.pdf?sequence=1 (2010, accessed 12 April 2019).

7. The Finnish Association for Palliative Care, https://www.sphy.fi/yhdistyksemme/historiaa/the-finnish-associationfor-pall/ (2019, accessed 12 April 2019).

8. Griffiths C. Deep nursing: a thoughtful, co-created nursing process. Nurs Manag 2017; 24(1): 27-30. 
9. Isaacson MJ and Minton ME. End-of-life communication. Nurses cocreating the closing composition with patients and families. ANS Adv Nurs Sci 2018; 41(1): 2-17.

10. Kilde B, Landmark BT and Grov EK. Flexible borders-co-creation in an interprofessional team: caring for patients with ALS in a palliative context. J Nurs Educ Pract 2017; 7(2): 126-134.

11. Lindahl B, Lidén E and Lindblad B-M. A meta-synthesis describing the relationships between patients, informal caregivers and health professionals in home-care settings. J Clin Nurs 2010; 20: 454-463.

12. Weaver K and Morse JM. Pragmatic utility: using analytical questions to explore the concept of ethical sensitivity. Res Theory Nurs Pract 2006; 20(3): 191.

13. Weaver K. Ethical sensitivity: state of knowledge and needs for further research. Nurs Ethics 2007; 14(2): $141-155$.

14. Lutzen K, Nordstrom G and Evertzon M. Moral sensitivity in nursing practice. Scand J Caring Sci 1995; 9(3): 131-138.

15. Rest JR. A psychologist looks at the teaching of ethics. Hastings Cent Rep 1982; 12(1): 29-36.

16. Scott PA. Perceiving the moral dimension of practice: insights from Murdoch, Vetlesen and Aristotle. Nurs Philos 2006; 7(3): 137-145.

17. Robichaux C. Developing ethical skills: from sensitivity to action. Crit Care Nurse 2012; 32(2): 65-72.

18. Rest JR. Moral development advances in research and theory. London: Praeger, 1986.

19. Narvaez D. Moral perception: a new construct? Paper presented at the annual meeting of the American Educational Research Association, New York, 8-12 April 1996.

20. Vetlesen AJ. Perception, empathy and judgement: an inquiry into the preconditions of moral performance. University Park, PA: Pennsylvania State University Press, 1994.

21. Rest JR. Background: theory and research. In: Rest J and Narvaez D (eds) Moral development in the professions. Hillsdale, NJ: Lawrence Erlbaum Associates, 1994.

22. Weaver K, Morse J and Mitcham C. Ethical sensitivity in professional practice: concept analysis. J Adv Nurs 2008; 62(5): 607-618.

23. Petersen L. See no evil: moral sensitivity in the formulation of business problems. Bus Ethics 2009; 18(4): 335-348.

24. Jagger S. Ethical sensitivity: a foundation for moral judgment. J Bus Ethics Educ 2011; 8(1): 13-30.

25. Dellaportas S, Jackling B, Leung P, et al. Developing an ethics education framework for accounting. J Bus Ethics Educ 2011; 8(1): 63-82.

26. Sparks JR and Hunt SD. Marketing researcher ethical sensitivity: conceptualization, measurement, and exploratory investigation. J Marketing 1998; 62(2): 92-109.

27. Milliken A. Ethical awareness: what it is and why it matters. Online J Issues Nurs 2018; 23(1): 1.

28. Poikkeus T, Numminen O, Suhonen R, et al. A mixed-method systematic review: support for ethical competence of nurses. $J$ Adv Nurs 2013; 70(2): 356-271.

29. Nortvedt. Subjectivity and vulnerability: reflections on the foundation of ethical sensibility. Nurs Philos 2003; 4(3): 222-230.

30. Kim Y-S, Park J-W, You M-A, et al. Sensitivity to ethical issues confronted by Korean hospital staff nurses. Nurs Ethics 2005; 12(6): 595-605.

31. Grace P. Nursing ethics. In: Grace P (ed.) Nursing ethics and professional responsibility in advanced practice. Sudbury, MA: Jones \& Bartlett, 2009, pp. 33-68.

32. Benner P. The roles of embodiment, emotion, and lifeworld for rationality and agency in nursing practice. Nurs Philo 2000; 1: 5-19.

33. Ersoy N and Göz F. The ethical sensitivity of nurses in Turkey. Nurs Ethics 2001; 8(4): 299-312.

34. Bergdahl E, Benzein E, Ternestedt BM and Andershed B. Development of nurses' abilities to reflect on how to create good caring relationships with patients in palliative care: an action research approach. Nurs Inquiry, 2011; 18(2): 111-122.

35. Eriksson K. Caring science. The science of caring. Stockholm: Liber AB, 2018. 
36. Harstäde CW, Blomberg K, Benzein E, et al. Dignity-conserving care actions in palliative care: an integrative review of Swedish research. Scand J Caring Sci 2018; 32(1): 8-23.

37. Lindström UÅ, Nyström LL, Zetterlund JE, et al. Theory of caritative caring, 2018. In: Alligood MR (ed.) Nursing theorists and their work. 9th ed. St. Louis, MO: Elsevier-Health Sciences Division, pp. 448-461.

38. Söderlund M. Caring. In: Wiklund Gustin L and Bergbom I (eds) Caring Science concepts in theory and practice. Lund: Studentlitteratur, 2012, pp. 115-126.

39. Edlund M. Dignity. In: Wiklund Gustin L and Bergbom I (eds) Caring science concepts in theory and praxis. Lund: Studentlitteratur, 2012, pp. 363-374.

40. Gadamer H-G. Truth and method in a selection. Göteborg: Daidalos AB, 1997.

41. Gadamer H-G. Truth and method. New York: Continuum, 1999.

42. Braun V and Clarke V. Using thematic analysis in psychology. Qual Res Psychol 2006; 3: 77-101.

43. Finnish National Advisory Board on Research Ethics. Responsible conduct of research and produces for handling allegations of misconduct in Finland-RCS guidelines. Helsinki, http://www.tenk.fi/sites/tenk.fi/files/HTK_ohje_ 2012.pdf (2012, accessed 9 January 2019).

44. Bergdahl E, Wikström B-M and Andershed B. Esthetic abilities: a way to describe abilities of expert nurses in palliative home care. $J$ of clinic Nurs, 2007; 16: 752-760.

45. Southall D. Creating new worlds: the importance of narrative in palliative care. J Palliat Care 2011; 27(4): 310-314. 